Available online at GSC Online Press Directory

GSC Biological and Pharmaceutical Sciences

e-ISSN: 2581-3250, CODEN (USA): GBPSC2

Journal homepage: https://www.gsconlinepress.com/journals/gscbps

(RESEARCH ARTICLE)

\title{
Phytochemical and biological investigation of 5 bioactive fractions of Caralluma acutangula, a medicinal plant used in traditional medicine in northern of Burkina Faso
}

\author{
Paré Dramane *, N'do Jotham Yhi-pênê and Hilou Adama \\ Laboratory of Biochemistry and Applied Chemistry (LABIOCA), UFR/SVT, 09 BP 848, Ouagadougou 09, University of \\ Ouagadougou, Ouagadougou, Burkina Faso.
}

Publication history: Received on 30 May 2020; revised on 11 June 2020; accepted on 18 June 2020

Article DOI: https://doi.org/10.30574/gscbps.2020.11.3.0159

\begin{abstract}
Caralluma acutangula is a medicinal plant used in traditional medicine in Africa against various pathologies. The objective of this study is to contribute to a better understanding of the biological activity of 5 fractions from Caralluma acutangula which can be used against the harmful effects of oxidative stress. Oxidative stress is most often associated with various diseases such as cancer, cardiovascular disease, diabetes, etc. So the 5 fractions, namely the Hexanic, Dichloromethane (DCM), ethyl acetate (AE), butanolic and aqueous fraction have been used for the determination of their antioxidant and anti-inflammatory potential through different method. Their phytochemical content was also determined. Flavonoids, alkaloids, tannins and coumarins have been detected in the different fractions. The ethyl acetate fraction of $C$. acutangula gives the best total polyphenol and flavonoid content respectively of $337.67 \pm 7.26 \mathrm{mg}$ EAG/g of extract and $21.65 \pm 1.16 \mathrm{mg}$ EQ/g of extract. For the inhibition of hydrogen peroxide, the fractions AE and DCM showed the best activity with $29.84 \pm 1.59$ and $28.53 \pm 2.81 \%$ greater inhibition than that of the gallic acid $(14.19 \pm$ 0.70 ) used as a reference. For the effect of the fractions on the lipoxygenase at the concentration of $1 \mathrm{mg} / \mathrm{ml}$, we have the hexanic fraction which exhibited the best activity with an inhibition of the enzyme at $67.21 \pm 4.13 \%$. The ethyl acetate fraction in general has shown good potential against oxidative stress. This fraction could therefore be used in the formulation of a phytomedicine against oxidative stress and its associated diseases.
\end{abstract}

Keywords: Caralluma acutangula; Oxidative stress; medicinal plant; Phytochemistry

\section{Introduction}

The multiple empirical knowledge on the plants accumulated during these past centuries allowed the Man at first to distinguish edible plants from toxic plants and secondly to know the plants with therapeutic virtue called medicinal plants. And, since their enormous use in traditional medicine, medicinal plants have always occupied a prime position in health care worldwide despite the progress of the pharmaceutical industry [1]. In some African countries plants have always been the main source of drugs (up to $90 \%$ of the population), for the treatment of various pathologies [2].

In Burkina Faso, more than 500 plants are used in traditional medicine after the ethnobotanical surveys carried out in the central part to Burkina Faso [3]. The enthusiasm displayed by the populations of tropical Africa towards the use of these plants is necessarily linked to their effectiveness against diseases.

Note that in today's world, in terms of health, there is a pressing need for new molecules in order to prevent and / or treat pathologies such as HIV-AIDS and opportunistic infections (tuberculosis, diarrhea, skin diseases), malaria, bacterial and fungal infections and diseases associated with oxidative stress [4,5].

\footnotetext{
${ }^{*}$ Corresponding author: Paré Dramane
}

Copyright (C) 2020 Author(s) retain the copyright of this article. This article is published under the terms of the Creative Commons Attribution Liscense 4.0. 
Oxidative stress is defined as the inability of the body to defend itself against reactive oxygen species due to the disturbance of endogenous balance between them and oxidizing agents. This imbalance leads to structural and functional damage, thus causing several diseases such as high blood pressure, cancers, diabetes, arteriosclerosis, rheumatism, gout, Alzheimer's disease, cardiovascular, respiratory and inflammatory diseases [6].

African societies, having developed in a tropical environment, had to find remedies to mitigate the effects of oxidative stress and associated diseases. Medicinal plants have constituted and still constitute an important arsenal for this battle [7].

Caralluma acutangula is a succulent perennial plant used in the north of Burkina Faso for the management of body weight [8]. Caralluma acutangula is used against boils, to heal wounds and it is considered a magic plant to protect livestock [9]. This species is also administered crude to children to treat chest pain [10]. The pregnanes glycosides isolated showed anti trypanosomiasis activity [11].

The objective of this study is to contribute to a better understanding of the biological activity of 5 fractions from Caralluma acutangula which can be used against the harmful effects of oxidative stress and associated diseases.

\section{Methods}

\subsection{Plant material, extraction and fractionation}

The whole plants of $C$. acutangula were harvested at Gorom gorom (a locality located in northern Burkina Faso at 400 $\mathrm{Km}$ on the road Ouagadougou (12 ${ }^{\circ} 29^{\prime} 42.7 \mathrm{~N}, 1^{\circ} 24^{\prime} 1.2 \mathrm{~W}$ ) during the period of March to April 2017 The specie was authenticated and a herbarium was deposited in the UFR / SVT under identification codes ID 17049.

The powder $(50 \mathrm{~g}$ ) of vegetable matter of Caralluma acutangula was put in bottles containing $500 \mathrm{ml}$ of absolute ethanol for a 24 hour of maceration. The ethanolic extract was obtained after filtration and vaporization of the solvent.

The ethanolic extract is fractionated using a series of solvents with increasing polarity, hexane, dichloromethane, ethyl acetate and butanol, using a separatory funnel. The crude extract is initially dissolved in water and then mixed with hexane, $(\mathrm{V} / \mathrm{V})$, after decantation the upper organic phase is recovered. This step is repeated three times. The hexane is subsequently evaporated to dryness at $40^{\circ} \mathrm{C}$ on a rotary evaporator, and the resulting extract is considered to be the hexane fraction. The lower aqueous phase is subjected to another fractionation with dichloromethane, ethyl acetate and butanol to give respectively the dichloromethane, ethyl acetate and butanolic fractions following the same steps as the first fractionation with hexane. The resulting raffinate represents the residual aqueous fraction. The solvents were removed under reduced pressure and then the concentrates were dried in an oven.

\subsection{Activity 1 phytochemistry}

\subsubsection{Secondary metabolites screening test}

These tests were carried out on the fractions of the extract. The procedures described by Ciulei (1982) [12] were used to identify the different chemical groups. So:

- The reaction with iron trichloride ( $\mathrm{FeCl} 3$ ) is used for the detection of tannins and polyphenols,

- The Shibata test for flavonoids,

- The Feiggl-Frehden test for coumarins,

- The Liebermann / Buchard test for triterpenes / steroids,

- The foam test for saponosides

\subsubsection{Total polyphenol content}

The total polyphenols of the extracts were determined by the method described by Singleton (1999) [13]. The extracts are dissolved in pure methanol to have a concentration of $10 \mathrm{mg} / \mathrm{mL}$, then diluted 1/100 in distilled water. A volume of $25 \mu \mathrm{L}$ of the diluted solution $(0.1 \mathrm{mg} / \mathrm{ml})$ was then mixed with $105 \mu \mathrm{L}$ of Folin reagent ciocalteu at $0.2 \mathrm{~N}$ and incubated for $5 \mathrm{~min} .100 \mu \mathrm{L}$ of a sodium carbonate solution at $75 \mathrm{~g} / \mathrm{L}$ in distilled water is then added and the mixture incubated for 2 hours. At the end of the incubation, the optical densities are read at $760 \mathrm{~nm}$ using a spectrophotometer. The total phenolic contents are determined using a reference curve with gallic acid as standard. In total, three (3) analyzes are performed for each extract and the result given is an average from these analyzes. The results are expressed in milligrams of gallic acid equivalent per $100 \mathrm{mg}$ of dry extract (mg EAG/100 mg). 


\subsubsection{Total flavonoid content}

The total flavonoid contents of the extracts were determined by the colorimetric method described by Arvouet-Grand et al. (1994) [14]. A volume of $75 \mu \mathrm{L}$ of $2 \% \mathrm{AlCl} 3$ in pure methanol is mixed with an equal volume of extract of $1 \mathrm{mg} /$ $\mathrm{ml}$ in methanol. The optical densities are read after $10 \mathrm{~min}$ at $415 \mathrm{~nm}$ using the spectrophotometer. Quercetin was used as the standard for the development of the calibration curve. In total, three (3) analyzes are performed for each extract and the result given is an average of the three readings. The results are expressed in milligrams of quercetin equivalent per $100 \mathrm{mg}$ of dry extract $(\mathrm{mg} \mathrm{EQ} / 100 \mathrm{mg})$

\subsubsection{Content of triterpene compounds}

The total triterpene content was evaluated according to the method described by Chang et al. in 2012 [15]. A volume of $300 \mu \mathrm{L}$ of vanillin-glacial acetic acid (5\%) is mixed with $200 \mu \mathrm{L}$ of the extracts dissolved in $100 \%$ methanol (final concentration $1 \mathrm{mg} / \mathrm{ml}$ ); $1 \mathrm{ml}$ of perchloric acid is added and the whole incubated at 60 degrees for 45 minutes. $4.5 \mathrm{ml}$ of glacial acetic acid are then added and the reading is done at $548 \mathrm{~nm}$ with the spectrophotometer. In total, three (3) analyzes are performed for each extract and the result given is an average of the three readings. The results are expressed in equivalent milligrams of ursolic acid per milligram of dry extract (mg E.A.U/mg)

\subsection{Activity 2 antioxidant potential}

\subsubsection{DPPH (2, 2diphenyl-1-picrylhydrazyl) anti-free radical activity}

The anti-radical activity of the ethanolic extracts $(1 \mathrm{mg} / \mathrm{ml})$ was evaluated by the DPPH method. (2,2diphenyl-1picrylhydrazyl) described by Vélazquez et al., (2003) [16]. This method is based on the reduction of the absorbance at $517 \mathrm{~nm}$ of the stable free radical DPPH, In the presence of a radical donor H. Three (03) tests were carried out by mixing $100 \mu \mathrm{l}$ of sample and $200 \mu \mathrm{l}$ of DPPH (20 mg/L in methanol). After 15 minutes of incubation, the absorbance is read at $517 \mathrm{~nm}$ against a blank ( $100 \mu \mathrm{L}$ of methanol and $200 \mu \mathrm{L}$ of DPPH) using a spectrophotometer. Quercetin and gallic acid were used as reference substances. Anti-free radical activity was expressed as a percentage of inhibition.

\subsubsection{Inhibition of Deoxyribose Degradation}

The power of the plant extract to trap the hydroxyl radical was evaluated using the trapping test for the degradation of deoxyribose as described by Perjési et al., (2011) [17]. The reaction mixture consisted of $100 \mu \mathrm{L}$ of extract $(1 \mathrm{mg} / \mathrm{ml}$ in $50 \mathrm{mM}$ phosphate buffer, pH 7.4), $100 \mu \mathrm{L}$ of EDTA (1.04 mM aqueous), $100 \mu \mathrm{L}$ of iron sulphate (100 mM aqueous), 100 $\mu \mathrm{L}$ of deoxyribose ( $60 \mathrm{mM}$ aqueous) and $100 \mu \mathrm{L}$ of hydrogen peroxide $(10 \mathrm{mM})$. The volume was made up to $1 \mathrm{~mL}$ with phosphate buffer, then the mixture was incubated $\left(37^{\circ} \mathrm{C}\right.$ for $\left.1 \mathrm{~h}\right)$. Trichloroacetic acid $(1 \mathrm{ml}, 15 \%$ aqueous $)$ and thiobarbituric acid ( $1 \mathrm{ml}, 0.675 \%$ in $25 \mathrm{mM}$ aqueous $\mathrm{NaOH})$ were added, then the whole was put back to incubation $\left(100^{\circ} \mathrm{C}\right.$. for $15 \mathrm{~min}$. ). After cooling in an ice bath $(5 \mathrm{~min})$, the tubes were centrifuged (3000 rpm for $\left.10 \mathrm{~min}\right)$ then 200 $\mu \mathrm{L}$ of the supernatant were transferred to 96 -well microplates. The trapping of deoxyribose degradation was measured using a spectrophotometer at $532 \mathrm{~nm}$ against a blank. Quercetin was used as the reference substance. The experiment was carried out in triplicate (independent tests) and the activity of the extract to trap the degradation of deoxyribose was expressed as a percentage of trapping the degradation of deoxyribose.

\subsubsection{Reducing power FRAP (Ferric Reducing Antioxidant Power)}

The determination of the reducing power of the plant extract was evaluated as described by Hinneburg et al., (2006) [18]. $1.25 \mathrm{ml}$ of phosphate buffer $(0.2 \mathrm{M} ; \mathrm{pH} 6.6)$ and $1.25 \mathrm{ml}$ of potassium hexacyanoferrate were added to a test tube containing $0.5 \mathrm{ml}$ of test extract $(1 \mathrm{mg} / \mathrm{ml})\left(1 \%\right.$ aqueous). The mixture was heated to $50^{\circ} \mathrm{C}$ in a water bath for 30 minutes. After cooling, trichloroacetic acid $(1.25 \mathrm{ml} ; 10 \%)$ was added and the mixture was centrifuged (2000 rpm for 10 minutes). Three aliquots $(125 \mu \mathrm{L})$ of the supernatant were transferred to a 96-well microplate to which were added $125 \mu \mathrm{L}$ of distilled water and then $25 \mu \mathrm{L}$ of $\mathrm{FeCl}_{3}(0.1 \%$ aqueous). The evaluation of the reducing power was carried out at $700 \mathrm{~nm}$ against a standard curve of ascorbic acid) using a spectrophotometer. The experiment was carried out in triplicate (independent tests) and the reducing activity of the extract was expressed in mmol Ascorbic Acid Equivalent per gram of extract (mmol EAA/g of extract)

\subsubsection{Hydrogen peroxide trapping}

The ability of the plant extract to trap hydrogen peroxide was evaluated according to the method described by Mohan et al., (2012) [19]. The reaction mixture consisting of $100 \mu \mathrm{L}$ of extract ( $200 \mu \mathrm{g} / \mathrm{ml}$ in $10 \mathrm{mM}$ phosphate buffer, $\mathrm{pH} 7.4$ ) and $100 \mu \mathrm{L}$ of hydrogen peroxide $(100 \mathrm{mM})$ was incubated for 10 minutes at ambient temperature. The residual hydrogen peroxide was measured at $230 \mathrm{~nm}$ against a blank containing only the phosphate buffer. The activity of the extract to trap hydrogen peroxide was expressed as a percentage of trapping of hydrogen peroxide compared to the 
control without extract. The experiment was carried out in triplicate (independent tests) and gallic acid was used as the reference substance.

\subsubsection{Inhibition of lipid peroxidation}

The inhibitory activity of lipid peroxidation (LPO) of the extracts were determined by the method of 2-thiobarbituric acid [20]. Iron dichloride $\left(\mathrm{FeCl}_{2}\right)$ with hydrogen peroxide $\mathrm{H}_{2} \mathrm{O}_{2}$ have been used to induce peroxidation of rat liver homogenate. In this method $0.2 \mathrm{~mL}$ of the extracts $(1.5 \mathrm{mg} / \mathrm{mL})$ was mixed with $1.0 \mathrm{~mL}$ liver homogenate in $1 \%$ Tris$\mathrm{HCl}$ buffer $(50 \mathrm{~mm}, \mathrm{pH} 7.40)$, then $50 \mu \mathrm{L}$ of $\mathrm{FeCl}_{2}(0.5 \mathrm{mM})$ and $50 \mu \mathrm{L}$ of $\mathrm{H}_{2} \mathrm{O}_{2}(0.5 \mathrm{mM})$ were added. The mixture was incubated at $37^{\circ} \mathrm{C}$ for 60 minutes, then $1 \mathrm{ml}$ of trichloroacetic acid (15\%) and $1 \mathrm{ml}$ of 2-thiobarbituric acid TBA (0.67\%) were added and the mixture is heated in boiling water for 15 minutes. The absorbances were read at $532 \mathrm{~nm}$ using the spectrophotometer. Quercetin was used as a positive control. The inhibitory activity of lipid peroxidation is calculated as a percentage of inhibition.

\subsection{Activity 3 Anti-inflammatory potential}

\subsubsection{Lipoxygenase inhibition}

The inhibitory activity of the extracts and fractions on the lipoxygenase was determined by the spectrophotometric method developed by Malterud et al., (2000) [21]. Briefly, the reaction medium consisted of a mixture of $100 \mu \mathrm{L}$ of extract or fraction prepared in the borate-methanol buffer (1\%) and $400 \mu \mathrm{L}$ of LOX (167 U ml-1). The mixture was incubated at room temperature for $2 \mathrm{~min}$ and the reaction is initiated by adding $500 \mu \mathrm{L}$ of the substrate solution (linoleic acid, $250 \mu \mathrm{M}$ in the borate buffer). The kinetics of the reaction are followed at $234 \mathrm{~nm}$ for 2 min. Inhibitory activity, expressed as a percentage of lipoxygenase inhibition.

\subsubsection{Xanthine oxidase inhibition}

The inhibitory activity of the extracts on the XO (EC.1.1.3.22) was evaluated according to the method described by Filha et al. (2006) [22]. The reaction mixture consists of $50 \mu \mathrm{L}$ of extract or fraction at the final concentration of $100 \mu \mathrm{g} / \mathrm{mL}$, $150 \mu \mathrm{L}$ of phosphate buffer ( $\mathrm{pH} 7.5,1 / 15 \mathrm{M})$ and $50 \mu \mathrm{L}$ of enzyme solution ( $0,28 \mathrm{U} / \mathrm{mL}$ prepared in buffer). After preincubation of the mixture at $25^{\circ} \mathrm{C}$ for $1 \mathrm{~min}$, the reaction is initiated by adding $250 \mu \mathrm{L}$ of a substrate solution (0.6 mM) and the absorbance is measured for three minutes. A blank is prepared without extract. The analyzes are carried out in triplicate. Quercetin and gallic acid are used as positive controls. Xanthine oxidase (XO) inhibitory activity, expressed as a percentage of inhibition.

\section{Results}

\subsection{Secondary metabolites screening test}

The phytochemical screening of the five fractions made it possible to note the presence of large groups of secondary metabolites such as flavonoids, steroids, saponosides, alkaloids, polyphenols and tannins (Table 1).

Table 1 Screening phytochimique

\begin{tabular}{lllllll}
\hline \multirow{2}{*}{$\begin{array}{c}\text { Type of } \\
\text { fraction }\end{array}$} & \multicolumn{2}{l}{ Phytochemical screening results } \\
\cline { 2 - 6 } & Tannins and polyphenol & Flavonoids & Coumarins & Saponosides & Sterols / triterpenes & Alkaloids \\
\hline Hex-Ca & + & - & - & + & + & - \\
Dcm-Ca & + & - & - & + & + & - \\
$\mathrm{AE}-\mathrm{Ca}$ & + & + & - & - & + \\
But-Ca & + & + & - & + & + \\
$\mathrm{AQ}-\mathrm{Ca}$ & + & - & + & + & +
\end{tabular}

Hex-ca: Hexanic fraction of C. acutangula; Dcm-ca: Dichloromethane fraction of C. acutangula; AE-Ca: Ethyl acetate fraction of C. acutangula; But-Ca: Butanolic fraction of $C$. acutangula, AQ-Ca: Aqueous fraction of $C$. acutangula,$+=$ detected ; - = no detected 


\subsection{Determination of secondary metabolites}

Total flavonoids and total polyphenols were quantified from standard quercetin and gallic acid standard curves. As for total triterpenes, a standard curve of ursolic acid was used. The results are shown in Figures 1 and 2.

The ethyl acetate fraction of $C$. acutangula gives the best total polyphenol and flavonoid content respectively of 337.67 $\pm 7.26 \mathrm{mg}$ EAG/g of extract and $21.65 \pm 1.16 \mathrm{mg}$ EQ/g of extract. The DCM fraction showed the lowest content both for total polyphenols and for total flavonoids.

The dichloromethane fraction showed the best total triterpene content with $11.01 \pm 0.37 \mathrm{mg}$ E.A.U/mg of extract. The aqueous fraction gave the lowest triterpene content.

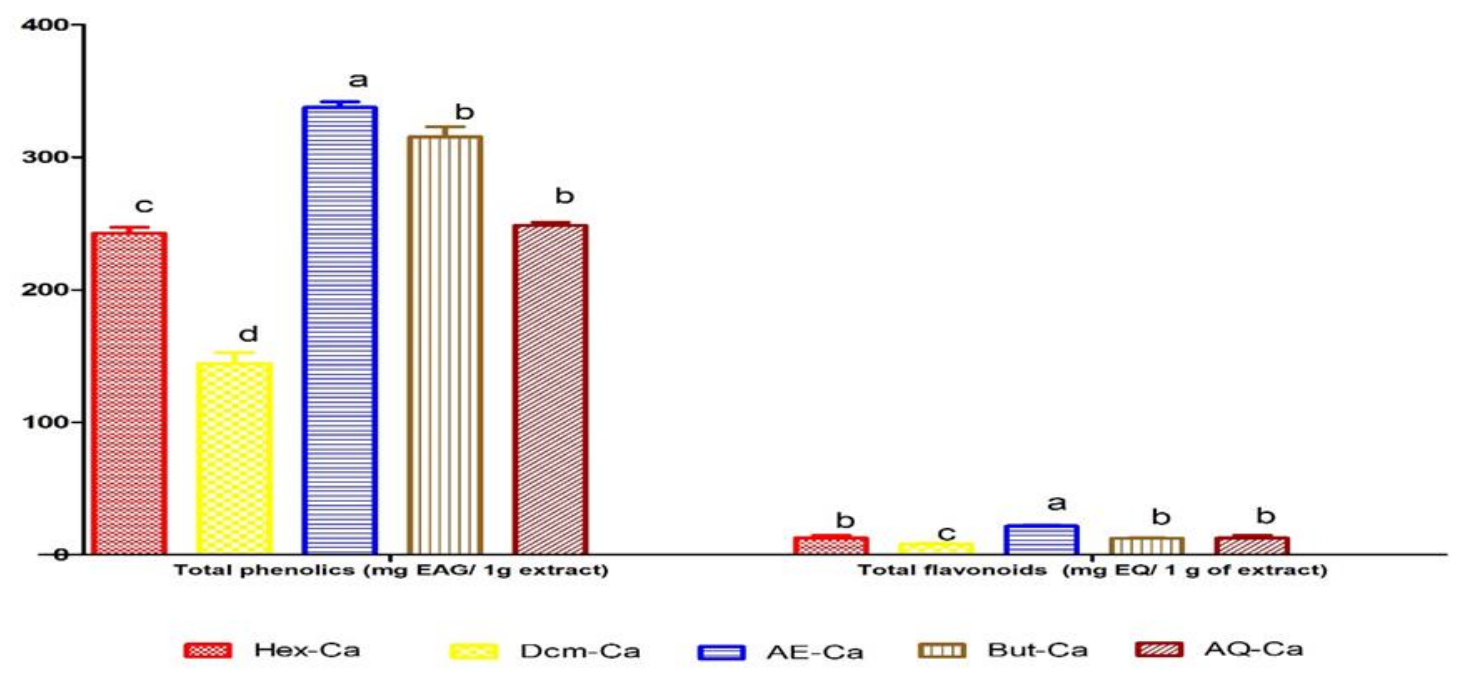

Figure 1 Phenolic content of $C$. acutangula fractions

Hex-ca: Hexanic fraction of C. acutangula; Dcm-ca: Dichloromethane fraction of C. acutangula; AE-Ca: Ethyl acetate fraction of C. acutangula; But-Ca: Butanolic fraction of C. acutangula, AQ-Ca: Aqueous fraction of C. acutangula

Mean values \pm Standard error of means of three experiments. Values with different superscript letters (a, b, c, d) differ significantly $(\mathrm{P}<0.05)$ for each measured parameter.

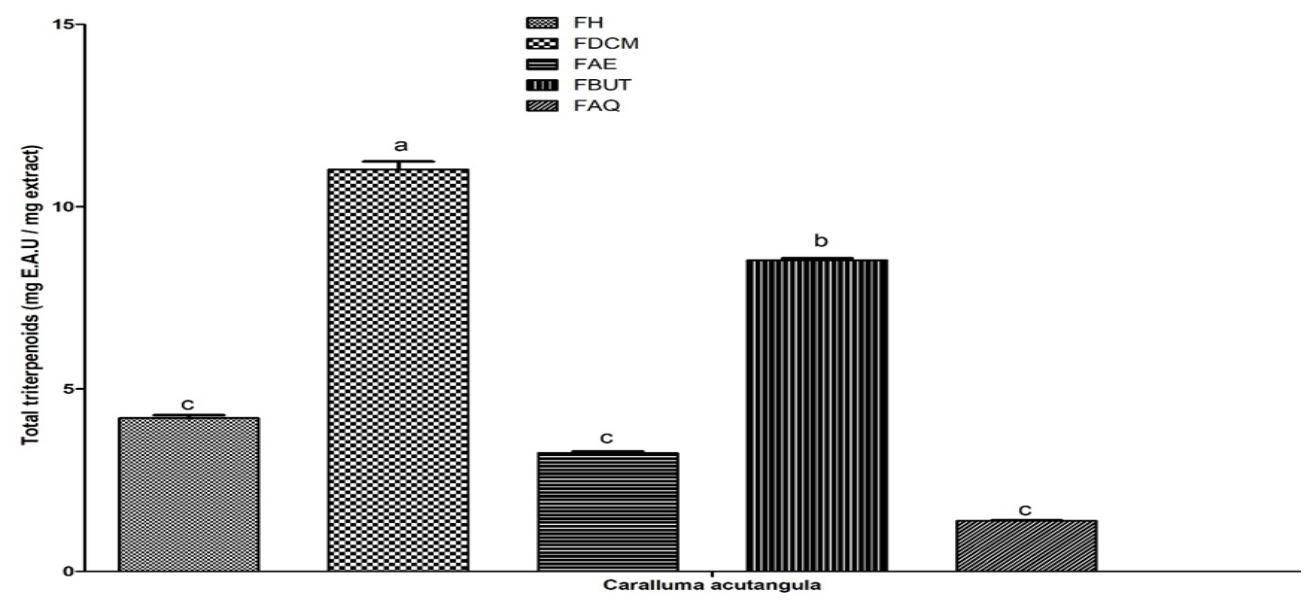

Figure 2 Total triterpene content

FH: Hexanic fraction of $C$. acutangula; FDCM: Dichloromethane fraction of $C$. acutangula; FAE: Ethyl acetate fraction of C. acutangula; FBut: Butanolic fraction of C. acutangula, FAQ: Aqueous fraction of C. acutangula 
Mean values \pm Standard error of means of three experiments. Values with different superscript letters (a, b, c) differ significantly $(\mathrm{P}<0.05)$ for each measured parameter

\subsection{Antioxidant property}

The antioxidant capacity of the fractions was evaluated in vitro by the use of different tests of antioxidant activities involving different mechanisms of action and ex vivo. In general, the Caralluma acutangula fractions have shown good antioxidant activity (Figure 3, 4, 5).

Indeed at $100 \mathrm{mg} / \mathrm{ml}$ fractions showed inhibitions of the degradation of desoxyribose greater than $50 \%$.

For the inhibition of hydrogen peroxide, the fractions AE-ca and DCM-ca showed the best activity with $29.84 \pm 1.59$ and $28.53 \pm 2.81 \%$ greater inhibition than that of the gallic acid $(14.19 \pm 0.70)$ used as a reference.

The reducing power of extracts measures their ability to reduce the ferric ion $\mathrm{Fe}^{3+}$ to ferrous ion $\mathrm{Fe}^{2+}$. The fractions presented good reducing activities but which is lower than that of Quercetin $(4.69 \pm 0.05 \mathrm{mmol}$ EAA/g of extract at 10 $\mathrm{mg} / \mathrm{ml}$ ) used as reference product.

The Hex, DCM, AE, But fraction showed good anti-free radical potential on the DPPH radical at $100 \mathrm{mg} / \mathrm{ml}$.

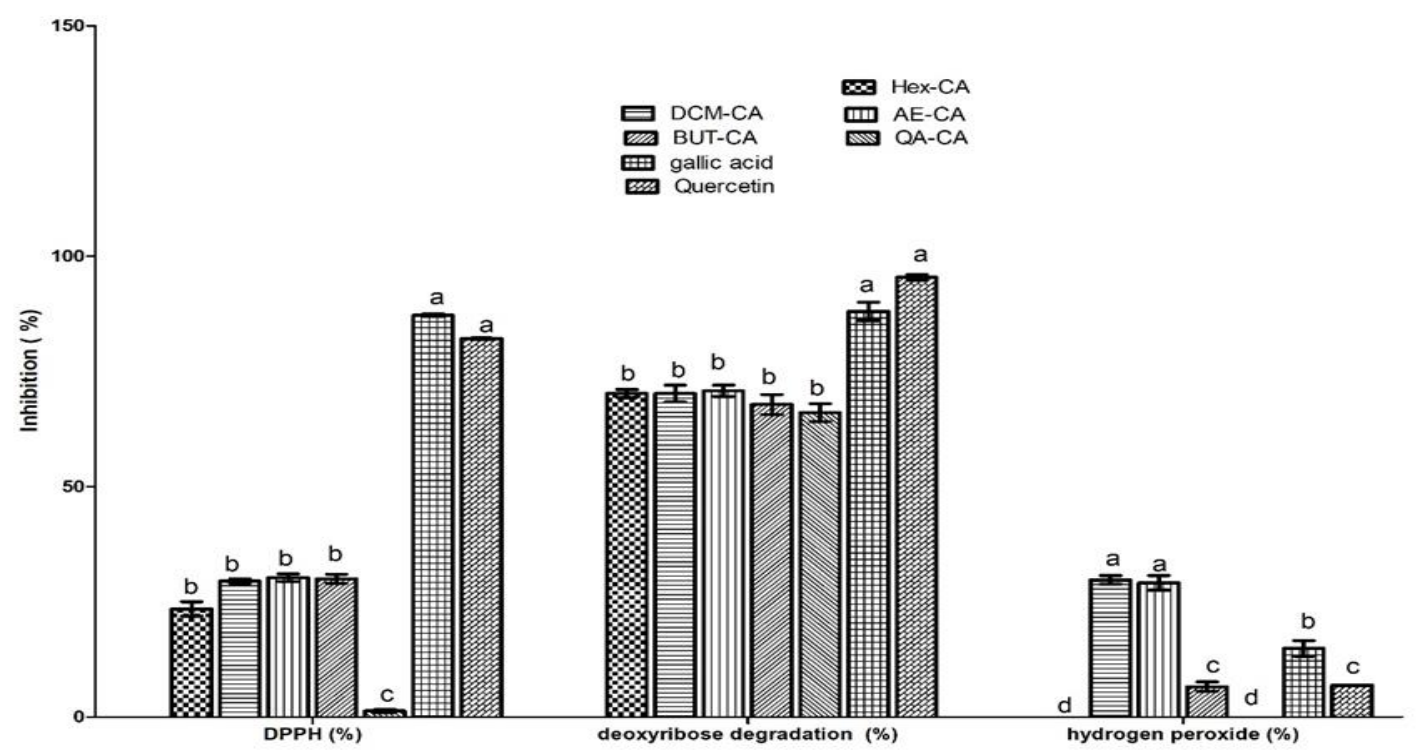

Figure 3 Antioxidant capacity of fractions

Hex-ca: Hexanic fraction of C. acutangula; Dcm-ca: Dichloromethane fraction of C. acutangula; AE-Ca: Ethyl acetate fraction of C. acutangula; But-Ca: Butanolic fraction of C. acutangula, AQ-Ca: Aqueous fraction of C. acutangula

Mean values \pm Standard error of means of three experiments. Values with different superscript letters (a, b, c, d) differ significantly $(\mathrm{P}<0.05)$ for each measured parameter 


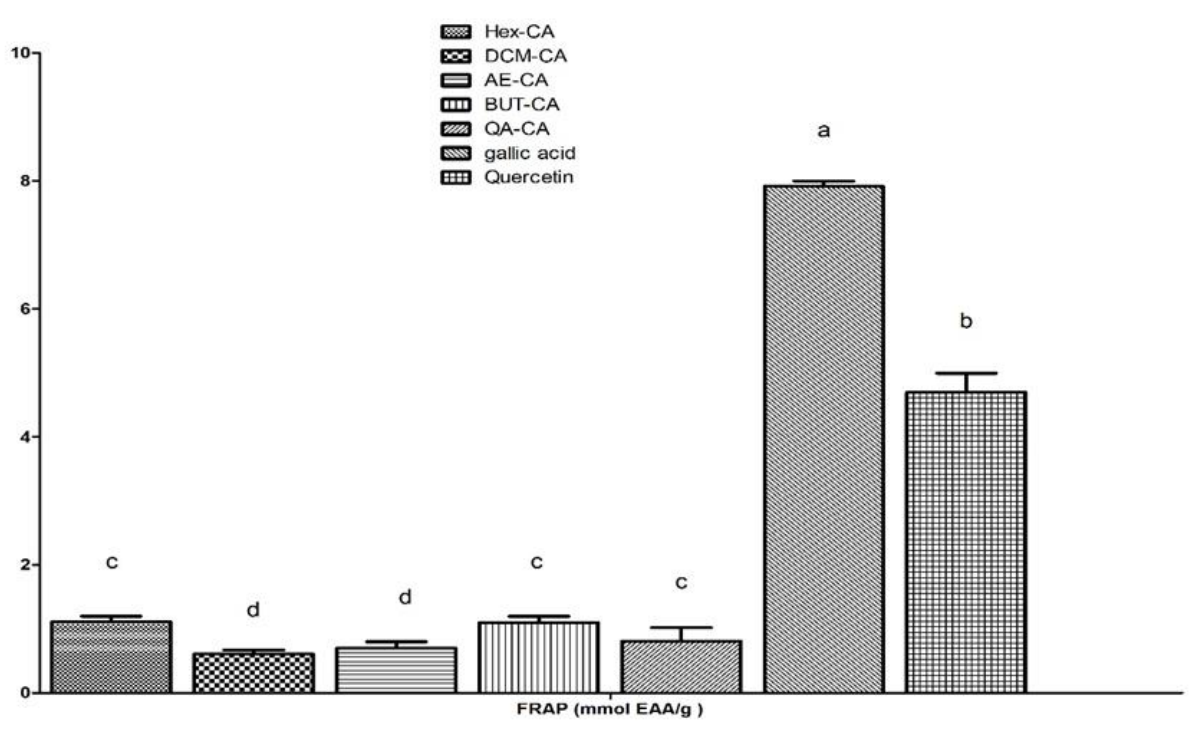

Figure 4 Reducing power of $C$. acutangula fractions

Hex-ca: Hexanic fraction of $C$. acutangula; Dcm-ca: Dichloromethane fraction of $C$. acutangula; AE-Ca: Ethyl acetate fraction of C. acutangula; But-Ca: Butanolic fraction of C. acutangula, AQ-Ca: Aqueous fraction of C. acutangula

Mean values \pm Standard error of means of three experiments. Values with different superscript letters (a, b, c, d) differ significantly $(\mathrm{P}<0.05)$ for each measured parameter

The figure 5 presents the capacity of the fractions to inhibit lipid peroxidation. The DCM Fraction of $C$. acutangula gave the best activity among the fractions of this plant with an inhibition of $76.42 \pm 1.12 \% 100 \mu \mathrm{g} / \mathrm{ml}$ against $91.78 \pm 1.52 \%$ and $90.67 \pm 0.98 \%$ at $10 \mu \mathrm{g} / \mathrm{ml}$ for quercetin and gallic acid respectively.

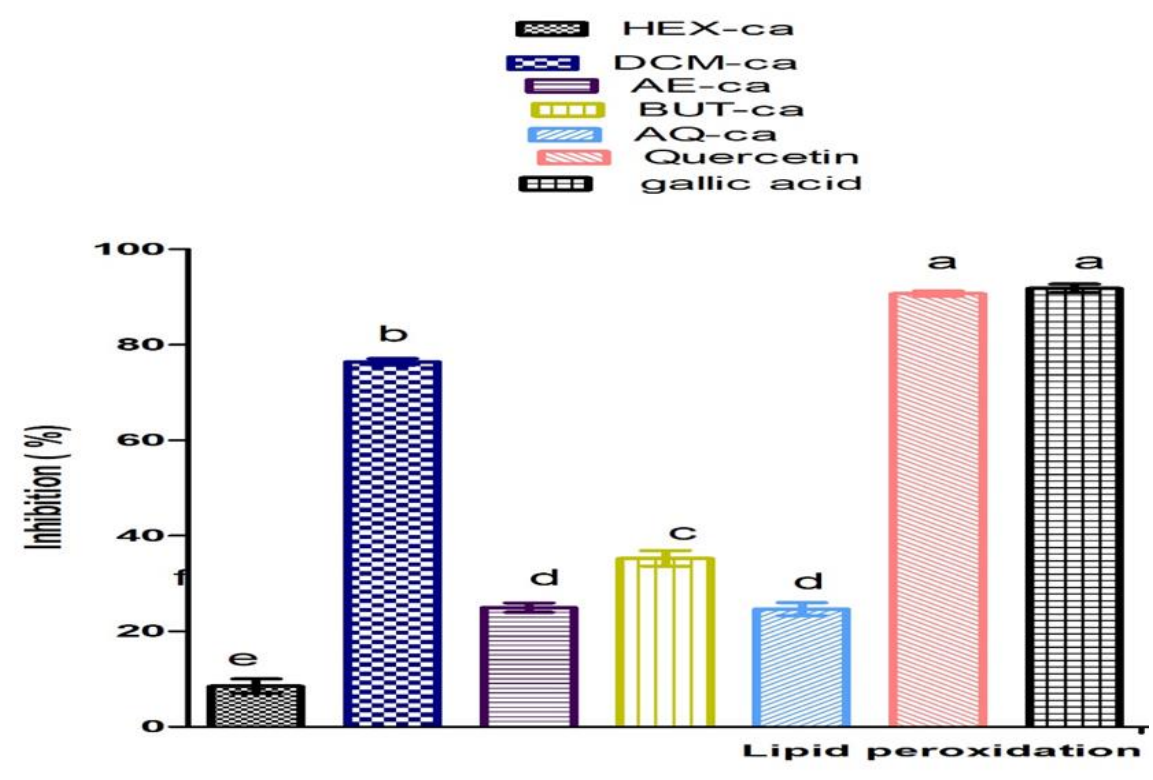

Figure 5 Inhibition of lipid peroxidation

Hex-ca: Hexanic fraction of $C$. acutangula; Dcm-ca: Dichloromethane fraction of $C$. acutangula; AE-Ca: Ethyl acetate fraction of C. acutangula; But-Ca: Butanolic fraction of C. acutangula, AQ-Ca: Aqueous fraction of C. acutangula

Mean values \pm Standard error of means of three experiments. Values with different superscript letters (a, b, c, d, e) differ significantly $(\mathrm{P}<0.05)$ for each measured parameter. 


\subsection{Anti-inflammatory property}

For the anti-inflammatory activity, the study consisted of an evaluation of the inhibitory power of the extracts on xanthine oxidase and lipoxygenase in vitro. These two enzymes are involved in inflammatory processes. Table 2 shows the action of the extracts on xanthine oxidase (XO) and lipoxygenase. The butanolic fraction of Caralluma acutangula at the concentration $100 \mu \mathrm{g} / \mathrm{mL}$ showed the best inhibiting activity of xanthine oxidase with $81.36 \pm 9.64 \%$ inhibition. The quercetin used as a reference exhibited a higher activity than that of the extracts $(90.90 \pm 00 \%)$. For the effect of the fractions on the lipoxygenase at the concentration of $1 \mathrm{mg} / \mathrm{ml}$, we have the hexanic fraction of $C$. acutangula which exhibited the best activity with an inhibition of the enzyme at $67.21 \pm 4.13 \%$. This fraction is as active as quercetin $(75.09 \pm 8.21 \%)$ used as reference substances and more active than gallic acid $(54.87 \pm 0.043 \%)$.

Table 2 Anti-inflammatory capacity of $C$. acutangula fractions

\begin{tabular}{lll}
\hline \multirow{2}{*}{ Fraction } & \multicolumn{2}{l}{ Inflammatory enzyme inhibition activity tests } \\
& Inhibition test of xanthine oxidase (\%) & Inhibition of lipoxygenase (\%) \\
\hline HEX-ca & $13.46 \pm 2.71 \mathrm{e}$ & $67.21 \pm 4.13 \mathrm{a}$ \\
DCM-ca & $61.36 \pm 1.92 \mathrm{c}$ & $47.31 \pm 6.6 \mathrm{c}$ \\
AE-ca & $53,17 \pm 4.19 \mathrm{~d}$ & $45.78 \pm 6.18 \mathrm{c}$ \\
BUT-ca & $81,36 \pm 9.64 \mathrm{~b}$ & $21.86 \pm 1.06 \mathrm{~d}$ \\
AQ-ca & $51.98 \pm 5.05 \mathrm{~d}$ & $42.13 \pm 7.34 \mathrm{c}$ \\
Gallic acid & ND & $54.87 \pm 0.043 \mathrm{~b}$ \\
Quercetin & $90.90 \pm 00 \mathrm{a}$ & $75.09 \pm 8.21 \mathrm{a}$ \\
\hline
\end{tabular}

Hex-ca: Hexanic fraction of C. acutangula; Dcm-ca: Dichloromethane fraction of C. acutangula; AE-Ca: Ethyl acetate fraction of C. acutangula; But-Ca: Butanolic fraction of C. acutangula, AQ-Ca: Aqueous fraction of C. acutangula

Mean values \pm Standard error of means of three experiments. Values with different superscript letters (a, b, c, d) differ significantly $(\mathrm{P}<0.05)$ for each measured parameter

\subsection{Statistical Analysis}

All results were expressed as the mean value of several independent experiments $(n=3) \pm$ standard deviation. For statistical analysis, Graph Pad Prism software (version 5.0) and MS Excel software were used to obtain standard curves and graphs, percentages of inhibition, averages and standard deviations. Anova one way followed by the Tukey test was used to measure the degree of statistical significance of the results. A significant difference was considered for $\mathrm{P}<0.05$

\section{Discussion}

Flavonoids, tannins, terpenes, alkaloids, saponosides were detected in the Caralluma acutangula fractions after phytochemical screening. These different metabolites have already shown several biological activities in various studies [23]. For the determination of phenolic compounds the ethyl acetate fraction gave the best contents, these results corroborate with those of Kharchouf et al., 2017 [24].., who also found this fraction was the richest in total polyphenol and total flavonoids among the other fractions. This assay therefore confirms the presence of flavonoids detected in this fraction after phytochemical screening.

Phenolic compounds generally have several biological properties such as anti-artherogenic, anti-inflammatory, hepatoprotective, antimicrobial, antiviral, antibacterial, anticarcinogenic, antithrombotic, cardioprotective and vasodilatory activities [25]...

Flavonoids notably have antioxidant, vasculoprotective, antihepatotoxic, antiallergic, anti-inflammatory, antiulcerative and even significant anti-tumor properties [26]. The ethyl acetate fraction being the richest in polyphenol and flavonoids could therefore be used to prevent these various pathologies. 
The sterols and triterpenoids were found in the different fractions of the extract with the dichloromethane fraction having the highest content. Many compounds of these two families are known for their anti-obesity activity [27]. The triterpenes found in these plant fractions could justify the use of these species against obesity.

The antioxidant property is the ability of certain molecules to neutralize free radicals responsible for oxidative stress. Our factions have shown good antioxidant activity through the neutralization of the DPPH radical, the reduction of ferric ion, the inhibition of the degradation of deoxyribose, hydrogen peroxide and lipid peroxidation.

In this study, the fractions of Caralluma acutangula by trapping apolar radicals (DPPH) could act within the membrane lipid or on the lipophilic surfaces of lipoproteins and prevent the initiation of lipid peroxidation caused by radicals. These fractions could be used to maintain the integrity of the cell membrane.

The reducing power of the various fractions studied is probably due to the presence of the hydroxyl group in the phenolic compounds, which can serve as an electron donor. The presence of polyphenol in these extracts could therefore explain the good reducing activity observed. Therefore, antioxidant compounds are considered to be reducers and inactivators of the oxidant [28].The extracts by inhibiting the degradation of deoxyribose could act by protecting the genetic material against the harmful effect of free radicals. Polyphenols with high stoichiometries have a significant capacity to trap free radicals by multiple transfers of Hydrogene atoms or electrons from the starting phenol and some of its oxidation products, as in the case of quercetin and rutin [29]. So the fractions of the extract would be rich in these kinds of molecules.

Inflammation is a set of reactional defense mechanisms of the body. But sometimes this inflammatory reaction exceeds its objectives and develops in an uncontrollable way leading to the appearance of different inflammatory diseases. Several enzymes such as Xanthine oxidase and lipoxygenase are involved in the inflammation process. The fractions showed good anti-inflammatory potential by exhibiting an inhibitory activity of Xanthine oxidase and lipoxygenase.

Many studies have shown that polyphenols and their metabolites also act as modulators of the signaling pathways for inflammation. Thus polyphenols could act on the enzymatic activities of the metabolism of arachidonic acid (AA): phospholipase A2, cyclooxygenase and lipoxygenase. They also act on the production of 'NO by modulating the activity of NOS. Inhibition of these enzymes by polyphenols reduces the production of AA, 'NO, prostaglandins and leukotrienes, mediators of inflammation [30]. In vitro studies have also shown that flavonoids act on several mediators of inflammation, like luteolin or apigenin inhibit the production of cytokines such as IL-4, IL-5 and IL-13, that quercetin inhibits the production of TNF- $\alpha$ by macrophages stimulated with lipopolysaccharide (LPS), that kaempferol inhibited the expression and secretion of TNF- $\alpha$, IL-1 $\beta$ or IL-6 in mast cells [31]... The presence of polyphenol and flavonoids in the different extract fractions could therefore justify the good anti-inflammatory activity observed.

\section{Conclusion}

From this study we can conclude tannins and polyphenols, terpenes and sterols, coumarins, alkaloids were all detected in the different fractions. The ethyl acetate fraction of Caralluma acutangula showed the highest content of total polyphenol and total flavonoids. They presented also good antioxidant and anti-inflammatory activity. These results could justify the use of this plant species in traditional medicines. An in-depth study for the determination of the different molecules contained in the ethyl acetate fraction would be worthy of interest.

\section{Compliance with ethical standards}

\section{Acknowledgments}

This work was supported by Laboratory of Biochemistry and Applied Chemistry in Burkina Faso.

\section{Disclosure of conflict of interest}

Authors have declared that no competing interests exist.

\section{References}

[1] Mekkiou R. (2005). Recherche et Détermination Structurale des Métabolites Secondaires d'espèces du Genre Genista (Fabaceae): G. saharae, G. ferox. Ph.D. thesis, University of Mentouri, Constantine, 1-215. 
[2] Tchamadeu MC, Dzeufiet PDD, Nouga CCK, Azebaze AGB, Allard JP, Girolami IT, Kamtchouing P and Dimo T. (2010). Hypoglycaemic effects of Mammea africana (Guttiferae) in diabetic rats. Journal of Ethnopharmacology, 127, 368-372.

[3] Nacoulma OG. (1996). Plantes médicinales et Pratiques médicinales Traditionnelles au Burkina. Ph.D Thesis, University of Ouagadougou, Burkina Faso, 1-328.

[4] Halliwell B and Guteride JMC. (1990). Role of free radicals and catalytic metals ions in humain disease: an overview. Methods in enzymology, 186, 1-85.

[5] Sweeney AP, Wyllie SG, Shalliker RA and Markhan JL. (2001). Xanthine oxidase inhibitory activity of selected Australian native plants. Journal of Ethnopharmacology, 75, 273-277.

[6] Cillard J and Cillard P. (2006). Mécanismes de la peroxydation lipidique et des anti-oxydations. OCL OleagineuxCorps gras. Lipides, 13(1), 24-30.

[7] Konaté K, Kiendrébéogo M, Ouattara MB, Souza A, Lamien-Meda A, Nongasida Y, Barro N, Millogo-Rasolodimby J and Nacoulma OG. (2011). Antibacterial potential of aqueous acetone extracts from five medicinal plants used traditionally to treat infectious diseases in Burkina Faso. Curr. Res. J. Biol. Sci, 3(5), 435-442.

[8] Pare D, Hilou A, Potârniche A, Mabozou K, Sárpataki O, Ouedraogo N, Blidaru AI, Taulescu A, Guenne S, Ioan M, Sanda A and Bogdan S. (2018). Caralluma Acutangula Prevents Body Weight Gain in Rats Feed on Hyperlipidic Diet, Bulletin UASVM Veterinary Medicine, 75(2), 1-10.

[9] Schmelzer GH and Gurib-Fakim A. (2013) Medicinal plants 2, PROTA.

[10] Wilson K, Bernard W, Hillary R and Gabriel K. (2014). A study of the medicinal plants used by the Marakwet Community in Kenya, Journal of Ethnobiology and Ethnomedicine, 10(1), 1-24.

[11] Abdel-Sattar E, Shehab NG, Ichino C, Kiyoharac H, Ishiyamad A, Otogurod K, Omurac S and Yamada H. (2009). Antitrypanosomal activity of some pregnane glycosides isolated from Caralluma species. Phytomedicine, 16, 659-664.

[12] Ciulei I. (1982). Pratical manuals on the industrial utilization of chemical and aromatic plants. Methodology for analysis of vegetable drugs Ed. ministry of chemical industry, Bucharest. 67.

[13] Singleton VL, Orthofer R and Lamuela-Raventos RM. (1999). Analysis of phenols and other oxidation substrates and antioxidants by means of Folin-Ciocalceu Reagent. Methods in Enzymology, 299, 152-178.

[14] Arvouet-Grand A, Vennat B, Pourrat A and Legret P. (1994). Standardisation d'un extrait de propolis et identification des principaux constituants. J. de Pharm. de Belgique, 49 (6), 462-468.

[15] Chang CL, Lin CS and Lai GH. (2012). Phytochemical Characteristics, Free Radical Scavenging Activities, and Neuroprotection of Five Medicinal Plant Extract. Evidence-Based Complementary and Alternative Medicine, 1-8.

[16] Velazquez E, Tournier HA, Mordiyavich-Buschiazza P, Saavedra G and Schinnella GR. (2003). Antioxydant activity of Paraguayan plants extracts. Fitoterapia, 74, 91-97.

[17] Perjési P and Rozmer Z. (2011). Kinetic analysis of some chalcones and synthetic chalcone analogues on the fenton-reaction initiated deoxyribose degradation assay. The Open Medicinal Chemistry Journal, 5, 61-7.

[18] Hinneburg I, Damien-Dordan HJ and Hiltunen R. (2006). Antioxidant activities of extracts from selected culinary herbs and spices. Food Chemistry, 97(1), 122-129.

[19] Mohan SC, Balamurugan V, Salini ST and Rekha R. (2012). Metal ion chelating activity and hydrogen peroxide scavenging activity of medicinal plant Kalanchoe pinnata. Journal of Chemical and Pharmaceutical Research, 4(1), 197-202.

[20] Ohkawa H, Ohishi N and Yagi K. (1979). Assay for lipid peroxidation in animal tissues by thiobarbituric acid reaction. Ann. Biochem, 95, 351-358.

[21] Malterud KE and Rydland KM. (2000). Inhibitors of 15-lipoxygenase from orange peel.Journal of Agricultural and Food Chemistry, 48, 5576-5580.

[22] Filha FZSIF, Vitolo LG and Fietto JAL. (2006). Saude-Guimaraes D.A. Xanthine oxidase inhibitory activity of Lychnophora species from Brazil ("Arnica"). J. Ethnopharmacol., 107, 79-82. 
[23] Mohammed Kawser Hossain, Ahmed Abdal Dayem, Jihae Han, Yingfu Yin, Kyeongseok Kim, Subbroto Kumar Saha, Gwang-Mo Yang, Hye Yeon Choi and Ssang-Goo Cho. (2016). Molecular Mechanisms of the Anti-Obesity and AntiDiabetic Properties of Flavonoids. Int J Mol Sci, 17(4), 569.

[24] Kharchouf S, Bouchador A, Drioiche A, Khiya Z, El Hilali F and Zai T. (2017). Phytochemistry and Antioxydante Activity of Stevia rebaudiana. Phytothérapie, 1-7.

[25] Middleton E, Dagger J and Kandaswami C. (2000). The effects of plant flavonoids on mammalian cells: implications or inflammation f, heart disease, and cancer. Am J Clin Nutr, 52 (4), 673-751.

[26] Jucá MM, Filho FMSC, Cunha de Almeida J, Mesquita DS, Moraes Barriga JR and Dias KCF. (2018). Flavonoids: biological activities and therapeutic potential, Natural Product Research, 1-14.

[27] Liu H, Guo X, Chu Y and Lu S. (2014). Heart protective effects and mechanism of quercetin preconditioning on anti-myocardial ischemia reperfusion (IR) injuries in rats. Gene, 545(1), 149-55.

[28] Xiao X, Wenxiu H, Siduo Z, Chuanhai T , Xiudong X, Juanmei Z and Mingsheng D. (2019). Increased Phenolic Content and Enhanced Antioxidant Activity in Fermented Glutinous Rice Supplemented with Fu Brick Tea. Molecules, 24, 671, 1-17.

[29] ACHAT S. (2013). Polyphénols de l'alimentation : extraction, pouvoir antioxydant et interactions avec des ions métalliques. Ph.D Thesis, University of A. MIRA-BEJAIA, Algeria, 1-261.

[30] Guo L, Wei G, Zhu J, Liao W, Leonard WJ, Zhao K, et al. (2009). IL-1 family members and STAT activators induce cytokine production by Th2, Th17, and Th1 cells. Proc. Natl. Acad. Sci. U.S.A, 106, 13463-13468.

[31] Gonzalez-Gallego MJ, Garcia-Mediavilla V, Sanchez-Campos S and Tunon MJ. (2010). Fruit polyphenols, immunity and inflammation. British Journal of Nutrition, 104, 15-27.

\section{How to cite this article}

Paré D, N'do JY and Hilou A. (2020). Phytochemical and biological investigation of 5 bioactive fractions of Caralluma acutangula, a medicinal plant used in traditional medicine in northern of Burkina Faso. GSC Biological and Pharmaceutical Sciences, 11(03), 81-91. 